\title{
TINGKAT MINAT SISWA SMP DALAM PEMBELAJARAN DARING BOLA BASKET
}

\author{
Idris Saepulloh $^{1}$, Setio Nugroho ${ }^{2}$, Irfan Zinat Achmad \\ FKIP-Universitas Singaperbangsa Karawang ${ }^{1,2,3}$ \\ Email: idrissaepulloh14@gmail.com
}

\begin{abstract}
ABSTRAK
Semua siswa memulai sesuatu dikarenakan adanya kemauan dari dalam sendiri, ajakan atau dorongan, baik dari diri sendiri maupun karena ajakan dari luar. Atau bisa disebut faktor intrinsik dan ekstrinsik, siswa biasanya cenderung hanya mengikuti kegiatan karena faktor diri sendiri maupun ajakan dari orang lain. Pada faktanya siswa melakukan sesuatu karena minat yang berasal dari dalam dirinya, dan hal ini menjadi dasar bahwa siswa melakukan kegiatan didasari karena minat. Tujuan dalam penelitian ini adalah untuk mengetahui tingkat minat siswa dalam pembelajaran daring bola basket di SMP Negeri 1 Pedes. Penelitian ini merupakan penelitian deskriptif kuantitatif. Dengan menggunakan metode survey dan teknik pengambilan data berupa angket/kuesioner. Populasi yang digunakan adalah kelas VIII SMP Negeri 1 Pedes yang berjumlah 283 siswa. Sampel yang digunakan dalam penelitian ini sebanyak 60 siswa dengan teknik sampling proportionate random sampling. Data dalam penelitian ini di analisis dengan menggunakan statistik deskriptif dengan presentase. Hasil penelitian menunjukan bahwa tingkat minat siswa dalam pembelajaran daring di SMP Negeri 1 Pedes Kabupaten Karawang secara keseluruhan berada pada kategori "Baik" dengan presentase sebesar (79\%).
\end{abstract}

Kata Kunci: Minat, Pembelajaran Daring, Bola Basket

\begin{abstract}
All students start something because of a will from within, an invitation or encouragement, both from themselves and because of an invitation from outside. Or it can be called intrinsic and extrinsic factors, students usually tend to only take part in activities due to self-factors or invitations from others. In fact, students do something because of interest that comes from within themselves, and this becomes the basis that students carry out activities based on interest. The purpose of this study was to determine the level of student interest in online learning basketball at SMP Negeri 1 Pedes. This research is quantitative descriptive. By using survey methods and data collection techniques in the form of a questionnaire. The population used was class VIII SMP Negeri 1 Pedes, amounting to 283 students. The sample used in this study were 60 students with the sampling technique proportionate random sampling. The data in this study were analyzed using descriptive statistics with percentages. The results showed that the level of student interest in online learning at SMP Negeri 1 Pedes, Karawang Regency was overall in the "Good" category with a percentage of $(79 \%)$.
\end{abstract}

Keywords: Interest, Online Learning, Basketball

Dipublikasikan Oleh :

UPT Publikasi dan Pengelolaan Jurnal

Universitas Islam Kalimantan Muhammad Arsyad Al-Banjari Banjarmasin 


\section{PENDAHULUAN}

Pendidikan ialah aktivitas yang berupa proses dalam mengembangkan kemampuan, sikap dan rohaniah yang mencangkup aspek mental, intelektual dan spiritual (Bangun, 2016). Pendidikan yang mampu mendukung pengembangan di masa depan adalah pendidikan yang mampu mengembangkan potensi siswa, sehingga orang yang bersangkutan dapat menghadapi dan menyelesaikan masalah kehidupan. Pendidikan harus mempengaruhi potensi kesadaran dan keterampilan potensial siswa (Jamaliah, 2019). Pendidikan adalah faktor yang penting dalam kehidupan manusia karena dengan adanya pendidikan diharapkan manusia dapat mengembangkan pengetahuan, keterampilan dan kreativitasnya. Melalui pendidikan, dapat diperoleh hal-hal baru yang dapat digunakan dalam proses keberlangsungan hidup manusia. Semakin berkembangnya ilmu pengetahuan dan teknologi, semakin bertambah pula usaha-usaha untuk meningkatkan kualitas pendidikan sesuai dengan perkembangan zaman.

Pendidikan jasmani adalah proses membuat seseorang dalam kegiatan jasmani memperoleh pertumbuhan dan perkembangan fisik yang secara sadar dilakukan dalam hal aspek kognitif, afektif dan psikomotorik (Rahman et al., 2020). Sedangkan pendapat dari pendapat lain pendidikan jasmani adalah bagian integral pada suatu proses pendidikan secara keseluruhan, merupakan prsoses pendidikan melalui aktivitas fisik yang dipilih untuk mengembangkan serta meningkatkan kemampuan organik, neuromaskuler, interoeratif, sosial dan emosional (Rahayu, 2013). Jadi pendidikan jasmani dapat diartikan sebagai proses pembelajaran yang mempunyai tujuantujuan tertentu dengan cara melibatkan kegiatan jasmani atau bahasa umumnya adalah olah raga.

Minat merupakan suatu rasa suka dan ketertarikan pada suatu hal atau aktivitas, tanpa ada yang menyuruh, dengan kata lain sistem pembelajaran yang ada dalam ekstrakurikuler tidak diperbolehkan mengandung paksaan (Valentino \& Iskandar, 2020). Dapat disimpulkan minat adalah sesuatu yang mendorong manusia untuk melakukan sesuatu tanpa adanya permintaan atau tanpa harus disuruh dan melakukan segala sesuatunya berdasarkan motivasi atau kesenangan sendiri. Terdapat beberapa bukti bahwa siswa memiliki minat yaitu, bergairah untuk belajar, tertarik pada pelajaran, tertarik pada guru, mempunyai inisiatif untuk belajar, kesegaran dalam belajar, konsentrasi dalam belajar, teliti dalam belajar, punya kemauan dalam belajar, dan ulet dalam belajar (Tafonao, 2018).

Belajar sangat penting bagi siswa karena mereka dapat meningkatkan kreativitas, pengetahuan, dan perilaku dengan baik. Belajar adalah bagian dari pendidikan dan detail, proses di mana lingkungan seseorang sengaja dikelola untuk belajar atau berpartisipasi dalam perilaku tertentu dalam kondisi tertentu atau sehingga dapat menanggapi situasi tertentu (Dwiyogo, 2010). Belajar dan pembelajaran merupakan suatu istilah yang memiliki keterkaitan yang sangat erat dan tidak dapat dipisahkan satu sama lain dalam proses pendidikan. Pembelajaran sesungguhnya merupakan kegiatan yang dilakukan untuk menciptakan suasana atau memberikan pelayanan agar siswa belajar. Untuk itu harus dipahami, bagaimana siswa memperoleh pengetahuan dari kegiatan belajarnya.

Belajar online adalah sistem pendidikan yang terisolasi dengan serangkaian metode pengajaran di mana kegiatan pendidikan dilakukan secara terpisah dari kegiatan belajar (Mustofa et al., 2019). Kemudian, pembelajaran pendidikan jasmani adalah pembelajaran keterampilan gerakan di mana gerakan manusia dimanipulasi dalam bentuk aktivitas fisik seperti, melalui permainan dan olahraga, yang berisi nilai-nilai, sikap positif (Rosdiani, 2015).

Defisnisi bola basket yaitu, bola basket dimainkan oleh dua tim yang masing-masing terdiri dari lima pemain, tujuan dari masing-masing tim adalah untuk mencetak angka ke keranjang, dan mencegah tim lawan untuk mencetak angka (Mahardika Bayu, 2016). Permainan bola basket merupakan permainan sederhana yang di mainkan oleh dua regu dan setiap regunya berjumlah lima orang pemain yang bertujuan untuk memasukkan bola ke basket lawan dan mencegah lawan memperoleh nilai. Permainan ini memerlukan gerakan- gerakan yang kompleks, artinya gerakangerakan yang dibutuhkan dalam permainan ini merupakan gerakan yang melibatkan banyak orang untuk bergerak secara fisik dan didukung oleh gerakan-gerakan kompleks yang saling mendukung. Misalnya sebelum melakukan shooting ataupun passing, anak harus terlebih dahulu mengetahui bagaimana cara memegang bola yang benar sehingga koordinasi kedua gerakan tersebut menyatu dengan baik. Disamping keterampilan yang bersifat fisik dalam permainan ini juga terkandung nilai-nilai yang bersifat psikis, sosial, seperti: daya juang, sportifitas, kerjasama, fairplay dan sebagainya.

Dipublikasikan Oleh : 
Pembelajaran pendidikan jasmani di SMP Negeri 1 Pedes bisa dikatakan baik. Tapi memang tidak semua siswa dapat dikatakan mempunyai pemahaman dan keterampilan yang baik, bahkan ada yang bisa dikatakan tidak paham dan kurang dalam keterampilan pada saat mengikuti pembelajaran pendidikan jasmani, dengan fasilitas yang bisa dibilang lengkap dengan materi yang baik dan cara penyampaian nya yang menarik. Siswa masih saja tidak terlalu paham dan kurang dalam pembelajaran penjas. Pada saat materi pembelajaran bola basket, siswa lebih sering menendang bola dibandingkan mendribble bola basket. Bedasarkan observasi yang didukung oleh guru pendidikan jasmani sebelum pandemic COVID-19 beberapa siswa ada yang mempunyai keterampilan yang baik karena mengikuti ekstrakurikuler, tapi kebanyakan siswa lebih senang bermain bola dan bola volley dengan alasan lebih seru dan mudah dimainkan. Hal seperti ini biasanya terjadi pada daerah yang memang lumayan jauh dari perkotaan, jadi permainan bola basket kurang dikenal dan seperti ada dan tidak ada eksistensinya. Terlebih lagi siswa saat ini melaksanakan pembelajaran menggunakan metode daring atau BDR (Belajar Dari Rumah) yang sangat sulit sekali untuk mengetahui minat siswa, apakah siswa ini mempunyai minat terhadap pembelajaran bola basket atau tidak. Maka sangat penting untuk mengetahui minat siswa karena dengan mengetahui minat siswa, kita bisa lebih mudah mengarahkan siswa dalam bidangnya dan sekalipun tidak berminat kita tahu bagaimana cara membuat siswa itu tertarik terhadap pembelajaran bola basket.

Terdapat beberapa penelitian terdahulu sebelumnya yang berjudul yaitu, Minat Siswa Kelas VIII Terhadap Pembelajaran Bola Basket Di SMP Negeri 2 Lendah Kabupaten Kulonprogo hasil penelitian menunjukkan minat siswa kelas VIII terhadap pembelajaran bolabasket di SMP Negeri 2 Lendah sebagian besar berada pada kategori sedang dengan persentase 39,5\% (Prasetyo, 2016), dan Minat Siswa Dalam Mengikuti Proses Pembelajaran Permainan Bola Basket Di Smp Negeri 16 Pontianak hasilnya menunjukan minat siswa dalam mengikuti proses pembelajaran permainan bola basket di Sekolah Menengah Pertama Negeri 16 Pontianak mencapai 33,72\% dalam kategori rendah (Ripin et al., 2013).

Dengan ini saya menyimpulkan bahwa adanya ketidak sesuaian dengan penelitian terdahulu. Karena minat siswa bukan hanya dipengaruhi oleh beberapa faktor tersebut tapi ada satu faktor yang memang bisa dibilang cukup berpengaruh yaitu faktor situasi dan kondisi. Karena pada saat ini situasi dan kondisi baik Indonesia maupun dunia sedang dalam darurat covid-19, maka dari itu pembelajaran daring atau online menjadi alternative agar pembelajaran dapat tetap dilakukan. Dengan situasi dan kondisi saat ini apakah dapat mempengaruhi minat siswa dalam pembelajaran penjas dengan materi pembelajaran bola basket.

\section{METODE}

Metode yang digunakan dalam penelitian ini adalah metode survei dan teknik pengumpulan data menggunakan kuesioner sebanyak 35 soal. Kuesioner merupakan teknik pengumpulan data yang efisien bila peneliti tahu dengan pasti variable yang akan diukur dan tahu apa yang bisa diharapkan dari responden. Skor dari akuisisi kuesioner kemudian dikelola dan dianalisis menggunakan statistik deskriptif yang diungkapkan dalam bentuk pengkategorian dan persentase. Dalam 35 butir soal terdapat dua faktor dan delapan indikator yaitu, faktor Intrinsik 1 terdapat tiga indikator yaitu, kemampuan, perangai, dan struktur fisik, sedangkan faktor ekstrinsik terdapat lima indikator yaitu, guru, fasilitas, teman sebaya, orang tua, dan kebiasaan.

Populasi sebanyak 283 kelas VII SMP Negeri 1 Pedes. Dalam pengambilan sampel dilakukan menggunakan teknik proportionate random sampling. Teknik Proportionate Random Sampling digunakan bila populasi mempunyai anggota/ unsur yang tidak homogen dan proporsional (Sugiyono, 2013). Apabila subjeknya kurang dari 100, lebih baik diambil semua sehingga penelitiannya merupakan penelitian populasi, selanjutnya jika subjeknya besar dapat diambil antara $10-15 \%$ atau $20-25 \%$ atau lebih (Arikunto, 2014). Sampel yang diambil $21 \%$ dari populasi dan jumlah sampel yang diambil sebanyak 60 siswa.

Instrumen penelitian ini dalam bentuk angket terdiri dari 35 butir pernyataan dengan menggunakan skor lima jawaban. Ada beberapa tahapan atau langkah yang harus diperhitungkan dalam persiapan instrumen, yaitu mendefinisikan konstruksi, faktor penyelidikan, kompilasi indikator dan persiapan deklarasi artikel (Irfan \& R Yuda, 2017).

Dipublikasikan Oleh : 
Teknik analisis yang digunakan dalam penelitian ini merupakan teknik anlasisis statistik deskriptif. Dalam perhitungan ini dibantu mengunakan microsoft excel 2013. Dalam penelitian ini peneliti menggunakan teknik TCR (Tingkat Capaian Responden) untuk mengalisis data yang sudah terkumpul. TCR adalah suatu metode penilaian dengan cara menyusun data yang dinilai berdasarkan peringkatnya pada berbagai sifat yang dinilai.

Dalam pengkategorian skor mengunakan lima kategori yaitu, sangat baik, baik, cukup baik, kurang baik, dan sangat tidak baik. Terdapat kriteria kategori penskoran menurut (Sugiyono, 2018).

Tabel 1. Tingkat Capaian Responden

\begin{tabular}{ccc}
\hline No & Interval Skor & Kategori \\
\hline 1 & $85 \%-100 \%$ & Sangat Baik \\
\hline 2 & $66 \%-84 \%$ & Baik \\
\hline 3 & $51 \%-65 \%$ & Cukup \\
\hline 4 & $36 \%-50 \%$ & Kurang Baik \\
\hline 5 & $<35 \%$ & Tidak Baik \\
\hline
\end{tabular}

HASIL DAN PEMBAHASAN

Tabel 2. Hasil Data Penelitian

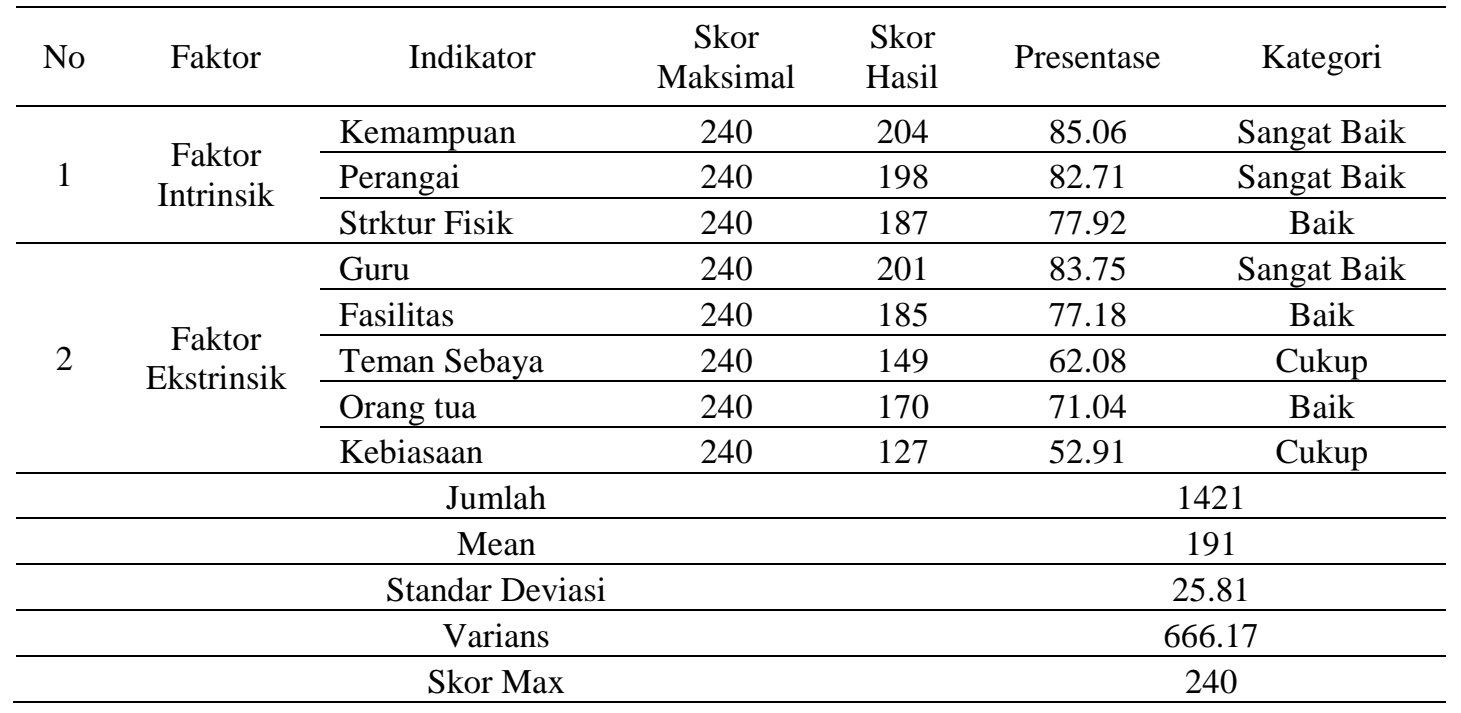

\section{Presentase Keseluruhan Indikator}

Dipublikasikan@leh UPT Publikasi1dan $F$ Universitas Islam Kaw....nton
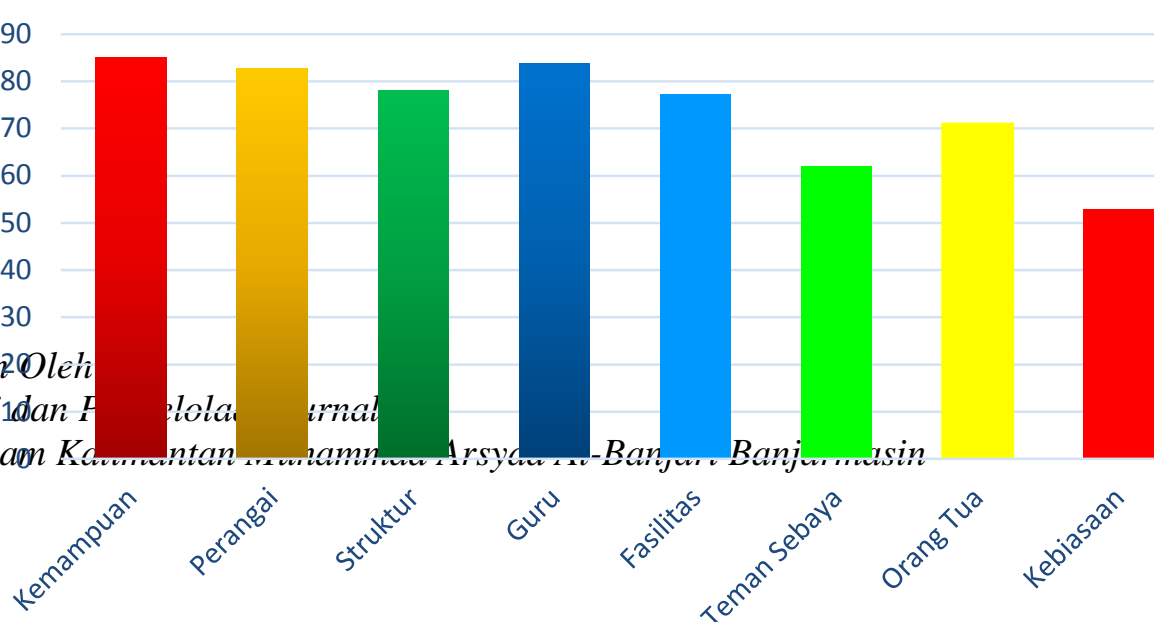


\section{Gambar 1. Hasil Persentase Dari Keseluruhan Indikator}

Dilihat dari tabel 2 dan gambar 1 pada faktor intrinsik yang terdiri dari, indikator kemampuan dengan persentase $(85,06 \%)$, perangai dengan persentase $(82,71 \%)$, struktur fisik dengan persentase $(77,92 \%)$. Sedangkan untuk faktor ekstrinsik terdiri dari, indikator guru dengan persentase $(83,75 \%)$, fasilitas dengan persentase $(77,18 \%)$, teman sebaya dengan persentase $(62,08 \%)$, orang tua dengan persentase $(71,04 \%)$, dan kebiasaan dengan persentase $(52,91 \%)$. Untuk secara keseluruhan yaitu sebesar $(79 \%)$ termasuk kedalam kategori baik.

Dengan sampel yang berjumlah 60 siswa dengan populasi lebih dari 100, diketahui bahwa tingkat minat siswa dalam pembelajaran daring bola basket di SMPN 1 Pedes Kabupaten Karawang sebagian besar mempunyai presentase 79\% pada kategori baik, hasil tersebut menunjukan bahwa sebagian besar siswa SMPN 1 Pedes memiliki tingkat minat yang baik dalam pembelajaran daring bola basket. Maka dari itu minat sangat berpengaruh dalam pembelajaran dikarenakan siswa tanpa mempunyai minat yang bagus akan menyebabkan mengganggu prestasi belajarnya dan tujuan pembelajaran tidak akan tercapai.

\section{PENUTUP}

Berdasarkan hasil penelitian dapat diketahui tingkat minat siswa dalam pembelajaran daring bola basket di SMPN 1 Pedes Kabupaten Karawang dipengaruhi oleh dua faktor intrinsik dan ekstrinsik, untuk faktor intrinsik dipengaruhi oleh (3) indikator diantaranya adalah indikator kemapuan (85\%) yang berkategori "sangat baik", indikator perangai (82\%) yang berkategori "sangat baik", indikator struktur fisik (77\%) yang berkategori "baik". Faktor ekstrinsik yang terdiri dari indikator guru (83\%) yang berkategori "sangat baik", indikator fasilitas (77\%) yang berkategori "baik", indikator teman sebaya (62\%) yang berkategori "cukup", indikator orang tua (71\%) yang berkategori "baik", dan indikator kebiasaan (52\%) yang berkategori "cukup". Dan untuk nilai keseluruhan yang dihitung dar 8 indikator terbagi menjadi 34 pernyataan maka diperoleh nilai rata-rata sebesar 79\%, sehingga dapat disimpulkan bahwa tingkat minat siswa dalam pembelajaran daring bola basket di SMPN 1 Pedes Kabupaten Karawang berkategori "baik" dengan presentase rata-rata (79\%).

Dari kesimpulan yang telah dijabarkan diatas makan peneliti mempunyai beberapa saran yaitu, Bagi siswa, penulis menyarankan untuk tetap bersemangat dan jauhi kata malas, belajar dirumah bukan berarti kalian harus bersantai Berikan respon yang baik dan cepat ketika guru memberikan tugas gerak pada saat pembelajaran daring, Bagi guru, penulis ingin menyarankan agar materi pembelajaran daring bola basket lebih kreatif dan menarik, untuk menghindari kejenuhan pada saat pembelajaran dan meningkatkan minat siswa dalam pembelajaran, dan bagi para peneliti hendaknya menggunakan indikator lebih rinci dan instrumen yang lebih bagus agar hasilnya lebih baik.

\section{REFERENSI}

Arikunto, S. (2014). Prosedur Penelitian (cetakan kelima belas). Jakarta: PT. Rineka Cipta.

Bangun, S. Y. (2016). Peran Pendidikan Jasmani Dan Olahraga Pada Lembaga Pendidikandi Indonesia. Publikasi Pendidikan, 6(3). https://doi.org/10.26858/publikan.v6i3.2270

Dwiyogo, W. D. (2010). Dimensi Teknologi Pembelajaran Pendidikan Jasmani dan Olahraga. Malang: Wineka Media.

Irfan, Z. A., \& R Yuda, K. A. (2017). Persepsi Mahasiswa PJKR Pada Matakuliah Pembelajaran Permainan Bola Voli Di Universitas Singaperbangsa Karawang. Journal Pedagogik Olahraga, 03(2), 1-13. https://doi.org/10.1017/CBO9781107415324.004

\section{Dipublikasikan Oleh :}


Jamaliah, N. (2019). Peningkatan Hasil Belajar Passing Bawah Bola Voli Melalui Torgamba Kabupaten Labuhan Batu Selatan Model Pbbt Dan Pbkl Siswa Kelas Viii Smpn 1. Universitas Islam Kalimantan Muhammad Arsyad Al-Banjari Banjarmasin, 3(2), 1-8.

Mahardika Bayu, D. (2016). Pengaruh Metode Pembelajaran Latihan Dan Motor Educability Terhadap Keterampilan Dribel Bola Basket. JUDIKA, 4(2), 292-242.

Mustofa, M. I., Chodzirin, M., Sayekti, L., \& Fauzan, R. (2019). Formulasi Model Perkuliahan Daring Sebagai Upaya Menekan Disparitas Kualitas Perguruan Tinggi. Walisongo Journal of Information Technology, 1(2), 151. https://doi.org/10.21580/wjit.2019.1.2.4067

Prasetyo, A. (2016). Minat Siswa Kelas VIII Terhadap Pembelajaran Bolabasket Di Smp Negeri 2 Lendah Kabupaten Kulon Progo. Pendidikan Jasmani Kesehatan Dan Rekreasi, 5(10).

Rahayu, E. T. (2013). Strategi Belajar Mengajar Penjaskes. Depdikbud: Jakarta.

Rahman, I., Gani, R. A., \& Achmad, I. Z. (2020). Persepsi Siswa Pada Pembelajaran Pendidikan Jasmani Olahraga dan Kesehatan Tingkat SMA. Jurnal Pendidikan Olahraga, 9(2), 144-154. https://doi.org/10.31571/jpo.v9i2.1898

Ripin, Wahyudi, \& Wati. (2013). Minat Siswa Dalam Mengikuti Proses Pembelajaran Permainan Bola Basket Di Smp Negeri 16 Pontianak. Pendidikan Pembelajaran Dan Khatulistiwa, 2(5), 1689-1699. /citations?view_op=view_citation\&continue=/scholar\%3Fhl\%3Dpt-

BR\%26as_sdt $\% 3 \mathrm{D} 0,5 \% 26 \mathrm{scilib} \% 3 \mathrm{D} 1 \&$ citilm=1\&citation_for_view=wS0xi2wAAAAJ:2osOgNQ5qMEC\&hl $=$ pt-BR\&oi $=\mathrm{p}$

Rosdiani, D. (2015). Kurikulum Pendidikan Jasmani. Bandung: Alfabeta.

Sugiyono, P. D. (2013). Statistik untuk Penelitian. CV. Alvabeta Bandung.

Sugiyono. (2018). Metode Penelitian Kualitatif, Kuantitatif dan $R \& D$. Alfabeta. Bandung.

Tafonao, T. (2018). Peranan Media Pembelajaran Dalam Meningkatkan Minat Belajar Mahasiswa. Jurnal Komunikasi Pendidikan, 2(2), 103. https://doi.org/10.32585/jkp.v2i2.113

Valentino, R. F., \& Iskandar. (2020). Identifikasi Minat Siswa Pada Ekstrakurikuler Sepak Bola. Jurnal Master Penjas Dan Olahraga, 1(April), 1-11.

Dipublikasikan Oleh :

UPT Publikasi dan Pengelolaan Jurnal

Universitas Islam Kalimantan Muhammad Arsyad Al-Banjari Banjarmasin 